\title{
A RECOMMENDATION-BASED PROPOSAL FOR IMPROVING ENERGY EFFICIENCY IN HOUSING
}

\author{
David García Retuerta
}

BISITE Digital Innovation Hub, University of Salamanca, Edificio Multiusos $I+D+i$, Calle Espejo 2, 37007 Salamanca, Spain

dvid@usal.es

ABSTRACT: $75 \%$ of buildings in the EU are not designed according to any energy efficiency code and around $45 \%$ of the world's energy is used in the residential sector. This is why one of Europe's biggest energy challenges is to include consumers at the heart of the energy system. The aim of this work is to develop a solution to a problem of such magnitude: to create a system of personalised recommendations to each consumer that contributes to improving the energy efficiency of their home.

The data will be obtained from sensorized homes in Salamanca. Some examples of possible recommendations are reducing the temperature of the thermostat, change the time at which the house is ventilated and raise the blinds at a certain time. The system developed is capable of providing these recommendations correctly an-d efficiently.

KeYwords: Artificial Intelligence; Energy Efficiency; Machine Learning; Recommending System.

\section{Introduction}

For retrieving energy consumption-related data, everything that surrounds the targeted house has to be linked to a data source and every aspect of the environment must be captured digitally. When a constant dataflow is obtained, 
an in-depth analysis must be carried out in order to capture the valuable information. We live in the era of big data and even bigger analytics.

However, a new method for transforming the obtained insights into real actions had to be developed. The proposed technique is based upon previous studies for modelling social behaviour. Previous studies have shown that environmentally friendly behaviours were most effective when they were accompanied by a provincial norm, as opposed to when they were accompanied by standard environmental messages [1-13]. The statistical capabilities of Artificial Intelligence for modelling group behaviours will be used for rewarding the most eco-friendly members of the group, and criticising the most wasteful ones.

In this work we propose a technique based on hybrid algorithms which combine machine learning methods with mathematical and statistical techniques for obtaining insights out of the raw data. Those algorithms will be used to change consumer behaviours and result in a decrease in energy consumption, without the need of altering the structure of the building or making construction works. Furthermore, consumer comfort will be taken into account by the recommender system which will increase the likelihood of changing the consumer habits in the long term [14-25]. Our main contributions are: Generating energy-related recommendations based on sensor's data automatically, providing the recommendation in the most effective way, maximising the likelihood of consumer's behaviour changes, and creating a public Python library for deep sensor's data preprocessing.

The main goal of this master's thesis is to provide some useful recommendations which are personalised for each user. The performance of the developed programs will be tested in the town of Salamanca (Spain) in the year 2020 , as the city council of Salamanca has agreed to implement it in some of its social housings [26-31].

\section{Objectives and Methodology}

The main goal of this project is to promote energy-efficient behaviours among its users. In addition, the secondary objectives (sorted by importance) are:

- Useful insights must be obtained from the retrieved data. 
- Users current energy-related behaviour must be correctly modelled.

- Basic energy demand predictions must be achieved.

- Gather data of sensors which are reliable and useful.

- Measure the level of satisfaction of the users and take them into account for the recommendations.

- Make an in-depth research into social behaviour modelling in order to deliver the recommendation in the most effective way.

- Provide a easy-to-use program which can be handily implemented in a real-life case.

- Find the relationship between certain changes in sensors' data and an increase/decrease in energy consumption.

The following methodology has been used: firstly a features selection is made, and a clustering algorithm selection is carried out. Afterwards, the results are validated and interpreted. Eventually, an output is produced (Figure).

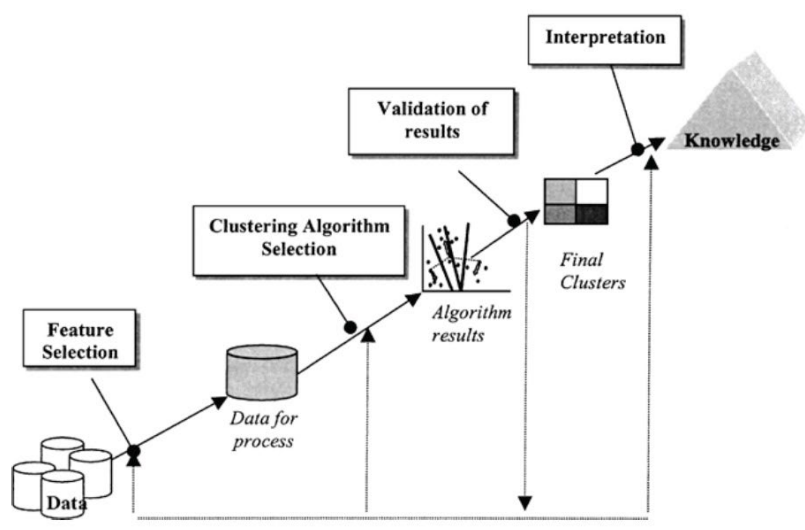

Figure 1. Steps of the clustering process.

\subsection{Contribution}

The innovative part of this work is the use of hybrid algorithms which combine machine learning methods with mathematical and statistical techniques for obtaining insights out of the raw data. Those algorithms will be used to change consumer behaviours and result in a decrease in energy 
consumption, without the need of altering the structure of the building or making construction works. Furthermore, consumer comfort will be taken into account by the recommendation system which will increase the likelihood of changing the consumer habits in the long term [32-43].

The following recommendations can be delivered to the users:

- Comparison of energy expenditure (weekly). The data is collected from the sensor established as the main one and compared with the rest of the neighbours, eliminating from the calculation those installations that do not have data or are not sufficient.

- Comparison of energy expenditure (weekly intervals). The data is collected from the sensor established as the main one and compared with the rest of the neighbours. For each installation, data from the meter is received grouped every 8 hours and compared with the data of the other installations.

- Thermostat survey and alert. The values of the thermostat are collected and those users that exceed a recommended value $\left(22^{\circ} \mathrm{C}\right)$ are sent a consumption recommendation and a percentage reduction (4-7\%).

- Ventilation recommendation. The indoor temperature and the weather forecast (Open WeatherMap) of the following 24 hours are measured. It is recommended to ventilate in the hour with the smaller difference between the interior temperature and the prediction, also it warns if at that hour it is possible that it rains.

Furthermore, if the indoors temperature exceeds the Tukey's Fences, a recommendation for ventilation is sent [44-51].

- Recommendation by humidity value. The humidity value is measured for each installation and, if it exceeds the Tukey's Fences, a recommendation is sent.

Furthermore, a public Python library has been developed and shared, it is available in $P y P i$. More details can be found in the ¡Error! No se encuentra el origen de la referencia. 


\section{Results Analysis}

A recommender system has been successfully developed in this work. The user must place certain IoT sensors, which will collect the data for the system, and will receive recommendations for increasing the energy efficiency of the house. The recommendations are inspired in the system of Singapore, which proved this idea to be a valid method [3]. Furthermore, this program broadens the scope of Singapore's method as, in addition to providing monthly recommendations, it delivers weekly and real-time recommendations [52-60].

- Monthly recommendations target the long-term habits of the user, promoting the consumer used to a eco-friendlier lifestyle.

- Weekly recommendations target long-term habits, as well as medium-term routines.

- On the other side, real-time recommendations' main goal is to end user's obsessions which are known to be a waste of energy, e.g., airing out the house at first time in the morning (the temperature difference indoors-outdoors is at its peak, which produces a big temperature drop inside of the house).

I believe such a complete system will be capable of improving the energy performance of dwells in Salamanca due to its wide range of recommendations. The real-life tests will show who recommendations are more useful for users and which recommendations are ignored. The program will then be fine-tuned, and the most useful recommendations will be presented in a more relevant context to the users. I consider that a raking system of «best users» could also be integrated for creating an attachment to users [61-75].

\section{Conclusion}

Energy saving or energy efficiency consists of using energy in a better way. That is, with the same amount of energy or with less, get the same results. Furthermore, saving money is important for many households, but finding the habits that will save energy at home is not always easy. Getting used to doing certain tasks on a daily basis can be complicated at first. 
With the purpose of finding a powerful and economic solution that provides the tools necessary for changing consumer habits, it was proposed the design and implementation of a recommender system of low cost and lower cost of implementation. In addition, recommendations had to be personalised by user so that the consumer gets engaged with the program for a time long enough to change their habits.

The designed system successfully provides personalised recommendations based on IoT sensors. The raw data was very unstructured due to several factors: failing sensors, different refresh times, etc. As a result, a public Python library has been developed and publicly published, so that people facing a similar problem can find a solution easily. The resulting data made it possible to create some testing recommendations which impact will be measured in the near future. Long-term recommendations are known to be effective based on the experiments carried out in Singapore, medium-term and real-time recommendations are believed to affect medium-term behaviours as well but no previous experiment has been made about this topic. Performance of the algorithms is satisfactory as real-time recommendations can be sent instantly and weekly analysis can be processed in a few seconds.

Real-world tests will be carried out in Salamanca (Spain) in order to finetune the recommendations for increasing the user's energy efficiency. The used data already provided useful information about the problem, but the user's reaction to the provided recommendations will also be taken into account.

A future research line is making predictions based on the current data. The preprocessing phase of the program provided many datasets which can be used for predicting future values of the sensors. A possible application is warning the user that they should be careful on the following day about a certain event.

\section{References}

1. Noah J Goldstein, Vladas Griskevicius, \& Robert B Cialdini. Invoking social norms: A social psychology perspective on improving hotels' linen-reuse programs. Cornell Hotel and Restaurant Administration Quarterly, 48(2):145-150, 2007.W.-K. Chen, Linear Networks and Systems (Book style). Belmont, CA: Wadsworth, 1993, pp. 123-135. 
2. Gerhard Reese, Kristina Loew, \& Georges Steffgen. A towel less: Social norms enhance pro-environmental behavior in hotels. The Journal of Social Psychology, 154(2):97-100, 2014.

3. Siew Eang Lee \& Priyadarsini Rajagopalan. Building energy efficiency labelling programme in singapore. Energy Policy, 36(10):3982-3992, 2008.

4. de Melo, Maximilian Jaderson, et al. «Robust and adaptive chatter free formation control of wheeled mobile robots with uncertainties.» ADCAIJ: Advances in Distributed Computing and Artificial Intelligence Journal 7.2 (2018): 27-42.

5. Ribeiro, Catarina, et al. «Customized normalization clustering meth-odology for consumers with heterogeneous characteristics.» ADCAIJ: Advances in Distributed Computing and Artificial Intelligence Journal 7.2 (2018): 53-69.

6. Becerril, Anahiby Anyel. «The value of our personal data in the Big Data and the Internet of all Things Era.» ADCAIJ: Advances in Distributed Computing and Artificial Intelligence Journal 7.2 (2018): 71-80.

7. Garcia, Ana Cristina Bicharra, \& Adriana Santarosa Vivacqua. «ACoPla: a Multiagent Simulator to Study Individual Strategies in Dynamic Situations.» ADCAIJ: Advances in Distributed Computing and Artificial Intelligence Journal 7.2: 81-91.

8. Casado-Vara, R., Novais, P., Gil, A. B., Prieto, J., \& Corchado, J. M. (2019). Distributed continuous-time fault estimation control for multiple devices in IoT networks. IEEE Access, 7, 11972-11984.

9. Jörg Bremer, Sebastian Lehnhoff. (2017) Decentralized Coalition Formation with Agent-based Combinatorial Heuristics. ADCAIJ: Advances in Distributed Computing and Artificial Intelligence Journal (ISSN: 2255-2863), Salamanca, v. 6, n. 3

10. Rafael Cauê Cardoso, Rafael Heitor Bordini. (2017) A Multi-Agent Extension of a Hierarchical Task Network Planning Formalism. ADCAIJ: Advances in Distributed Computing and Artificial Intelligence Journal (ISSN: 2255-2863), Salamanca, v. 6, n. 2

11. Enyo Gonçalves, Mariela Cortés, Marcos De Oliveira, Nécio Veras, Mário Falcão, Jaelson Castro (2017). An Analysis of Software Agents, Environments and Applications School: Retrospective, Relevance, and Trends. ADCAIJ: Advances in Distributed Computing and Artificial Intelligence Journal (ISSN: 2255-2863), Salamanca, v. 6, n. 2

12. Eduardo Porto Teixeira, Eder M. N. Goncalves, Diana F. Adamatti (2017). Ulises: A Agent-Based System For Timbre Classification. ADCAIJ: Advances in Distributed Computing and Artificial Intelligence Journal (ISSN: 2255-2863), Salamanca, v. 6 , n. 2 
13. Lucas Fernando Souza de Castro, Gleifer Vaz Alves, André Pinz Borges (2017). Using trust degree for agents in order to assign spots in a Smart Parking. ADCAIJ: Advances in Distributed Computing and Artificial Intelligence Journal (ISSN: 2255-2863), Salamanca, v. 6, n. 2

14. Aversa, R., Petrescu, R. V., Akash, B., Bucinell, R., Corchado, J., Berto, F., .. \& Petrescu, F. I. (2017). Kinematics and forces to a new model forging manipulator. American Journal of Applied Sciences, 14(1), 60-80.

15. Li, T., Sun, S., Bolić, M., \& Corchado, J. M. (2016). Algorithm design for parallel implementation of the SMC-PHD filter. Signal Processing, 119, 115-127.

16. Corchado, J. M., Aiken, J., Corchado, E. S., \& Fdez-Riverola, F. (2005). Evaluating the air-sea interactions and fluxes using an instance-based reasoning system. AI Communications, 18(4), 247-256.

17. Costa, Â., Novais, P., Corchado, J. M., \& Neves, J. (2011). Increased performance and better patient attendance in an hospital with the use of smart agendas. Logic Journal of IGPL, 20(4), 689-698.

18. Rodríguez, S., de La Prieta, F., Tapia, D. I., \& Corchado, J. M. (2010, June). Agents and computer vision for processing stereoscopic images. In International Conference on Hybrid Artificial Intelligence Systems (pp. 93-100). Springer, Berlin, Heidelberg.

19. Corchado, J. M., Corchado, E. S., \& Pellicer, M. A. (2004, September). Design of cooperative agents for mobile devices. In International Conference on Cooperative Design, Visualization and Engineering (pp. 205-212). Springer, Berlin, Heidelberg.

20. Corchado, J. M., Laza, R., Borrajo, L., Yañez, J. C., De Luis, A., \& Gonzalez-Bedia, M. (2003, July). Agent-based web engineering. In International Conference on Web Engineering (pp. 17-25). Springer, Berlin, Heidelberg.

21. Fdez-Riverola, F., \& Corchado, J. M. (2003). Forecasting red tides using an hybrid neuro-symbolic system. AI Communications, 16(4), 221-233.

22. González-Briones, A., Prieto, J., De La Prieta, F., Herrera-Viedma, E., \& Corchado, J. (2018). Energy optimization using a case-based reasoning strategy. Sensors, 18(3), 865.

23. Díaz, F., Fdez-Riverola, F., Glez-Peña, D., \& Corchado, J. M. (2006, September). Using fuzzy patterns for gene selection and data reduction on microarray data. In International Conference on Intelligent Data Engineering and Automated Learning (pp. 1087-1094). Springer, Berlin, Heidelberg.

24. Koetsier, J., Corchado, E., MacDonald, D., Corchado, J., \& Fyfe, C. (2004, June). Kernel maximum likelihood hebbian learning. In International Conference on Computational Science (pp. 650-653). Springer, Berlin, Heidelberg. 
25. Pavón, J., \& Corchado, J. (2004). Agents for the web. International journal of Web engineering and technology, 1(4), 393-396.

26. Fdez-Riverola, F., Díaz, F., Borrajo, M. L., Yáñez, J. C., \& Corchado, J. M. (2005, August). Improving gene selection in microarray data analysis using fuzzy patterns inside a cbr system. In International Conference on Case-Based Reasoning (pp. 191-205). Springer, Berlin, Heidelberg.

27. Fernández-Riverola, F., \& Corchado, J. M. (2003, November). Employing tsk fuzzy models to automate the revision stage of a cbr system. In Conference on Technology Transfer (pp. 302-311). Springer, Berlin, Heidelberg.

28. Corchado, J. M., \& Aiken, J. (1998). Expert system for modelling water masses. In WORKSHOP ON DATA MINING. GLASGOW, SCOTLAND.

29. Corchado, J. M., \& Aiken, J. (1998). Neuro-symbolic reasoning for real time oceanographic problems. In CONFERENCE ON DATA MINING. IEE, SAVOY PLACE, LONDON.

30. Corchado, J. M. (1998). Models for integrating artificial intelligence approaches. DOCTORAL CONSORTIUM ON KNOWLEDGE DISCOVERY AND DATA MINING. PAISLEY, UK.

31. Borrajo, M. L., Corchado, J. M., Yáñez, J. C., Fdez-Riverola, F., \& Díaz, F. (2005, August). Autonomous internal control system for small to medium firms. In International Conference on Case-Based Reasoning (pp. 106-121). Springer, Berlin, Heidelberg.

32. Fdez-Riverola, F., Díaz, F., \& Corchado, J. M. (2004, November). Applying rough sets reduction techniques to the construction of a fuzzy rule base for case based reasoning. In Ibero-American Conference on Artificial Intelligence (pp. 83-92). Springer, Berlin, Heidelberg.

33. Corchado, J., \& Lees, B. (1998). Case based reasoning opportunities and technologies. In CONFERENCE ON KNOWLEDGE DISCOVERY. IEE, SAVOY PLACE, LONDON.

34. Corchado, J., \& Lees, B. (1998). Artificial neural networks in pattern recognition: multicollinearity and heterocedasticity. In COLLOQUIUM ON KNOWLEDGE DISCOVERY. LONDON, UK.

35. Corchado, J., \& Lees, B. (1998). An overview of intelligent frameworks. In COLLOQUIUM ON INTELLIGENT SYSTEMS. IEE, LONDON, UK.

36. Corchado, J. M., \& Lees, B. (1998). Probis: Modelling intelligence with hybrid systems. In WORKSHOP ON DATA MINING. University of GLASGOW, SCOTLAND, UK. 
37. Corchado, J. (1998). Real time forecast with intelligent systems. In CONFERENCE ON KNOWLEDGE DISCOVERY. IEE, SAVOY PLACE, LONDON.

38. Corchado, J. M. (1997). Bdi multiagent hybrid architecture for project management. In IEEE COLLOQUIUM ON KNOWLEDGE DISCOVERY AND DATA MINING. LONDON ENGLAND.

39. Corchado, J. M. (1997). System for decision making: a practical case. In CONFERENCE ON KNOWLEDGE DISCOVERY AND DATA MINING. IEE, LONDON, UK.

40. Corchado, J. (1995). Cbr systems, an overview. In INTERNATIONAL CONFERENCE ON INTELLIGENT SYSTEMS. LONDON, ENGLAND, UK.

41. Li, T., Sun, S., Corchado, J. M., \& Siyau, M. F. (2014, July). A particle dyeing approach for track continuity for the SMC-PHD filter. In 17th International Conference on Information Fusion (FUSION) (pp. 1-8). IEEE.

42. Corchado, E. S., Corchado, J. M., Sáiz, L., \& Lara, A. (2004, July). A beta-cooperative cbr system for constructing a business management model. In Industrial Conference on Data Mining (pp. 42-49). Springer, Berlin, Heidelberg.

43. Corchado, J. M., \& Lees, B. (1998). Integration ai models. In WORKSHOP ON KNOWLEDGE DISCOVERY AND DATA MINING. PML-NERC, PLYMOUTHLONDON, UK.

44. Corchado, J. M., \& Lees, B. (1998). Cognitive models for integrating artificial intelligence approaches. In AII WORKSHOP ON KNOWLEDGE DISCOVERY. GLASGOW, UK.

45. Corchado, J. M. (1997). Real time forecast with intelligent systems: Cbrs and anns. In WORKSHOP ON ARTIFICIAL NEURAL NETWORKS. ABERDEEN (pp. $1-3)$.

46. Casado-Vara, R., Prieto, J., De la Prieta, F., \& Corchado, J. M. (2018). How blockchain improves the supply chain: Case study alimentary supply chain. Procedia computer science, 134, 393-398.

47. Corchado, J. M. (1996). Case-base reasoning recommendation system. In IEEE COLLOQUIUM ON KNOWLEDGE DISCOVERY. LONDON, UK.

48. Corchado, J. M. (1995). Neuro-symbolic reasoning-a solution for complex problemas. In INTERNATIONAL CONFERENCE ON INTELLIGENT SYSTEMS. LONDON, UK.

49. Corchado, J. M. (1995). Multi agent tools: a case study. In IEEE COLLOQUIUM ON KNOWLEDGE DISCOVERY. LONDON ENGLAND, UK.

50. Casado-Vara, R., Prieto-Castrillo, F., \& Corchado, J. M. (2018). A game theory approach for cooperative control to improve data quality and false data detection 
in WSN. International Journal of Robust and Nonlinear Control, 28(16), 50875102.

51. Casado-Vara, R., Chamoso, P., De la Prieta, F., Prieto, J., \& Corchado, J. M. (2019). Non-linear adaptive closed-loop control system for improved efficiency in IoT-blockchain management. Information Fusion, 49, 227-239.

52. Li, T., Sun, S., Corchado, J. M., \& Siyau, M. F. (2014, July). Random finite setbased Bayesian filters using magnitude-adaptive target birth intensity. In 17 th International Conference on Information Fusion (FUSION) (pp. 1-8). IEEE.

53. Rodríguez, S., Gil, O., De La Prieta, F., Zato, C., Corchado, J. M., Vega, P., \& Francisco, M. (2010, May). People detection and stereoscopic analysis using MAS. In 2010 IEEE 14th International Conference on Intelligent Engineering Systems (pp. 159-164). IEEE.

54. Guillén, J. H., del Rey, A. M., \& Casado-Vara, R. (2019). Security Countermeasures of a SCIRAS Model for Advanced Malware Propagation. IEEE Access, 7 , 135472-135478.

55. Corchado, J. M. (1996). Artificial intelligence models: composed systems as a solution. In IEEE COLLOQUIUM ON KNOWLEDGE DISCOVERY. LONDON ENGLAND, UK.

56. Casado-Vara, R., De la Prieta, F., Rodriguez, S., Prieto, J., \& Corchado, J. M. (2018, June). Cooperative Algorithm to Improve Temperature Control in Recovery Unit of Healthcare Facilities. In International Symposium on Distributed Computing and Artificial Intelligence (pp. 49-62). Springer, Cham.

57. Corchado, J. M. (1995). Hybrid cbr system for real-time temperature forecasting in the ocean. In IEEE COLLOQUIUM ON KNOWLEDGE DISCOVERY. LONDON, UK.

58. Corchado, J. M. (1995). A distributed recommendation system assos. In IEEE COLLOQUIUM ON KNOWLEDGE DISCOVERY. IEE, LONDON, UK.

59. Corchado, J. M. (1995). The use of kernel methods in cbr systems. In INTERNATIONAL CONFERENCE ON INTELLIGENT SYSTEMS. LONDON ENGLAND UK.

60. Corchado, J. M. (1995). Case based reasoning systems: automatic construction. In INTERNATIONAL CONFERENCE ON INTELLIGENT SYSTEMS. LONDON ENGLAND UK.

61. Casado-Vara, R., de la Prieta, F., Prieto, J., \& Corchado, J. M. (2018, November). Blockchain framework for IoT data quality via edge computing. In Proceedings of the 1st Workshop on Blockchain-enabled Networked Sensor Systems (pp. 19-24). ACM. 
62. Gil, A. B., De la Prieta, F., \& Rodríguez, S. (2011). Automatic Learning Object Extraction and Classification in Heterogeneous Environments. In Highlights in Practical Applications of Agents and Multiagent Systems (pp. 109-116). Springer, Berlin, Heidelberg.

63. Rodríguez, S., Tapia, D. I., Sanz, E., Zato, C., de la Prieta, F., \& Gil, O. (2010, July). Cloud computing integrated into service-oriented multi-agent architecture. In International Conference on Information Technology for Balanced Automation Systems (pp. 251-259). Springer, Berlin, Heidelberg.

64. Garcia, R. F., Rolle, J. L. C., Castelo, J. P., \& Gomez, M. R. (2014). On the monitoring task of solar thermal fluid transfer systems using NN based models and rule based techniques. Engineering Applications of Artificial Intelligence, 27, 129-136..

65. Mazuelas, S., Lorenzo, R. M., Bahillo, A., Fernández, P., Prieto, J., \& Abril, E. J. (2010). Topology Assessment Provided by Weighted Barycentric Parameters in Harsh Environment Wireless Location Systems. IEEE Transactions on Signal Processing, 58(7), 3842-3857. doi:10.1109/TSP.2010.2047394

66. Prieto, J., Alonso, A. A., la Rosa, de, R., \& Carrera, A. (2014). Adaptive Framework for Uncertainy Analysis in Electromagnetic Field Measurements. Radiation Protection Dosimetry. doi:10.1093/rpd/ncu260

67. Prieto, J., Bahillo, A., Mazuelas, S., Blas, J., Fernández, P., \& Lorenzo, R. M. (2008). RTS/CTS mechanism with IEEE 802.11 for indoor location. Presented at the NAV08/ILA37, The Navigation Conference \& Exhibition.

68. Prieto, J., Bahillo, A., Mazuelas, S., Fernández, P., Lorenzo, R. M., \& Abril, E. J. (2012a). Self-Calibration of TOA/Distance Relationship for Wireless Localization in Harsh Environments. Presented at the 2012 IEEE International Conference on Communications (ICC 2012).

69. Prieto, J., Bahillo, A., Mazuelas, S., Lorenzo, R. M., Blas, J., \& Fernández, P. (2009a). Adding indoor location capabilities to an IEEE 802.11 WLAN using real-time RTT measurements (pp. 113-119). IEEE Press. Retrieved from http:// dl.acm.org/citation.cfm? $\mathrm{id}=1689059.1689083 \&$ coll $=\mathrm{DL} \& \mathrm{dl}=\mathrm{GUIDE} \& \mathrm{CFID}=$ 647274630\&CFTOKEN $=45917612$

70. Bullon, Juan, et al. «Manufacturing processes in the textile industry. Expert Systems for fabrics production.» ADCAIJ: Advances in Distributed Computing and Artificial Intelligence Journal 6.4 (2017): 15-23.

71. Souza de Castro, Lucas Fernando, Gleifer Vaz Alves, \& André Pinz Borges. «Using trust degree for agents in order to assign spots in a Smart Parking.» (2017). 
72. Moung, Ervin. «A Comparison of the YCBCR Color Space with Gray Scale for Face Recognition for Surveillance Applications.» ADCAIJ: Advances in Distributed Computing and Artificial Intelligence Journal [Online], 6.4 (2017): 25-33.

73. Kethareswaran, V., \& C. SANKAR RAM. «An Indian Perspective on the adverse impact of Internet of Things (IoT).» ADCAIJ: Advances in Distributed Computing and Artificial Intelligence Journal 6.4 (2017): 35-40.

74. Crespo-Ramos, M. J., MachóN-GonzáLez, I., LóPez-GarcíA, H., \& Calvo-Rolle, J. L. (2013). Detection of locally relevant variables using SOM-NG algorithm. Engineering Applications of Artificial Intelligence, 26(8), 1992-2000.

75. Casado-Vara, R., Martin-del Rey, A., Affes, S., Prieto, J., \& Corchado, J. M. (2020). IoT network slicing on virtual layers of homogeneous data for improved algorithm operation in smart buildings. Future Generation Computer Systems, 102, 965-977. 
